\title{
Do contexto à contextualização: dinâmicas das historicidades dos processos comunicacionais - Apresentação do Dossiê
}

\author{
Bruno Souza Leal \\ Pesquisador permanente do PPGCOM/UFMG, na linha de pesquisa "Textualidades midiáticas". Coordena o Núcleo de Estudos \\ Tramas Comunicacionais: Narrativa e Experiência. Possui graduação em Comunicação Social, mestrado e doutorado em Estudos \\ Literários pela Universidade Federal de Minas Gerais e pós-doutorado em Ciências da Comunicação pela Unisinos. Bolsista de \\ Produtividade do CNPq. \\ <brunosleal@gmail.com
}

\section{Igor Sacramento}

Doutor (2012) e mestre (2008) em Comunicação e Cultura pela Escola de Comunicação da Universidade Federal do Rio de Janeiro (ECO/UFRJ). É pesquisador do Laboratório de Pesquisa em Comunicação e Saúde do Instituto de Comunicação e Informação Científica e Tecnológica em Saúde da Fundação Oswaldo Cruz (Laces/lcict/Fiocruz) e professor do quadro permanente do Programa de Pós-Graduação em Comunicação e Cultura da Universidade Federal do Rio de Janeiro (PPGCOM/ UFRJ). Na UFRJ, atua também como pesquisador do Núcleo de Estudos e Projetos em Comunicação (NEPCOM/ECO/UFRJ). Na Fiocruz, trabalha, ainda, como editor associado da Revista Eletrônica de Comunicação, Informação \& Inovação em Saúde (RECIIS), como professor colaborador do Programa de Pós-Graduação em Comunicação e Informação em Saúde (PPGICS) e como coordenador do curso de especialização em Comunicação e Saúde (C\&S), em parceria com Janine Miranda Cardoso. <igorsacramento@gmail.com>

\section{Itania Gomes}

Doutora em Comunicação e Cultura Contemporâneas pela Universidade Federal da Bahia (2000) e bolsista produtividade em Pesquisa do CNPq. É membro titular do Comitê de Assessoramento Artes, Ciência da Informação e Comunicação (CNPq). Coordena o Centro de Pesquisa em Estudos Culturais e Transformações na Comunicação (http://tracc-ufba.com.br). Realizou Estágio Sênior na Columbia University/USA, 2013/2014 e pós-doutorado em 2006/2007 na Université Sorbonne-Nouvelle (Paris III), ambos com bolsa CAPES.

<itania@ufba.br>

Em um dos seus artigos seminais, Reinhart Koselleck reflete sobre a importância e os contornos de uma história dos conceitos como forma de apreender mudanças históricas de sentidos, dos usos dos termos e a desnaturalizar significados e relações sociais que os envolvem. No âmbito dos estudos em Comunicação, o chamado do historiador alemão lança luz para pelo menos dois problemas distintos: sobre a historicidade propriamente dita dos termos que frequentam nossos trabalhos e também sobre a atenção a ser dada àquelas expressões que nos parecem pouco problemáticas. É o caso de "contexto", que, apesar de ser bastante frequente nos mais diferentes trabalhos, surge quase sempre como um termo pacificado, como sinônimo de pano-defundo. No entanto, como os artigos aqui reunidos demonstram, uma vez que se 
reconhece os jogos dinâmicos entre passado, presente e futuro, entre memória e esquecimento, e circuitos comunicativos mais amplos que as condições de produção de uma obra ou seu diálogo sincrônico com o presente, o contexto passa a abrigar relações complexas e desafiadoras. Menos que algo simples, de recuperação do já dado, o contexto surge como contextualização, ou seja, como um agir sobre os fenômenos, processos e produtos, capaz de dar-lhe forma, informá-los, e de fazer emergir demandas poéticas, éticas e estéticas, abrigando necessariamente as distintas temporalidades da obra e dos seus interlocutores (produtores, instituições, consumidores, outras obras, etc.).

As diferentes aproximações e apropriações do contexto neste dossiê buscam configurar caminhos para apreendermos as complexidades e desafios que envolvem a contextualização. Os artigos nascem do trabalho conjunto dos pesquisadores que compõem a rede "Historicidades dos processos comunicacionais", que é constituída por grupos de pesquisa de 7 diferentes Programas de Pós-Graduação em Comunicação do país: Fiocruz, UFBA, UFOP, UFMG, UFPI, UFRB e UFRJ. Desde abril de 2015, a Rede Historicidades promove dois encontros de trabalho anuais, todos com vistas a desenvolver abordagens teóricas e metodológicas que superem visadas eminentemente presentistas dos fenômenos comunicacionais. A Rede, como seu nome indica, tem na temporalidade seu lugar de encontro e trabalho, num esforço de apreender a experiência temporal configurada em produtos e processos comunicacionais diversos. Diferentes referências teóricas alimentam esse esforço, desde os Estudos Culturais, como as importantes contribuições de Raymond Williams, até obras filosóficas do peso das de Martin Heidegger e Paul Ricoeur, passando pelo diálogo crítico com o pensamento historiográfico. Nos trabalhos aqui reunidos, essas e outras referências se fazem presentes.

O dossiê conta com artigos centrados em dois eixos. O primeiro é composto por três artigos que discutem teoricamente as possibilidades e desafios da análise contextual na pesquisa em comunicação. Ana Paula Goulart Ribeiro (UFRJ), Bruno Martins (UFMG) e Elton Antunes (UFMG), em “Linguagem, sentido e contexto: comunicação e história", partem das teorias da linguagem para pensar uma noção de contexto histórico no âmbito da pesquisa em comunicação que são se dê de maneira automática, como algo que aprisiona e estabiliza a narrativa histórica do fenômeno comunicacional. Eles buscam inverter a relação com o processo de contextualização: não mais como "moldura" ou "fundo" sociocultural em que se dão os processos comunicacionais, mas como"figura" que dá vida aos textos, o que dá dinamicidade à sua materialidade, tornando-os assim justamente práticas sociais. 
Em "Aproximações à instabilidade temporal do contexto", Bruno Souza Leal (UFMG) e Carlos Alberto de Carvalho (UFMG) desenvolvem a ideia de que a contextualização vai além da dicotomia "dentro" e "fora" do texto, mas diz respeito a complexos atravessamentos de temporalidades. Embora o contexto seja algo frequentemente associado ao passado, como "pano de fundo", é preciso considerar a multiplicidade temporal dos textos, o que leva a observar que o futuro (imaginado, projetado, esperado, etc) é um componente fundamental da análise contextual.

Na sequência, em "Historicidade e Contexto em perspectiva Histórica e Comunicacional", Marialva Carlos Barbosa (UFRJ) e Ana Regina Rego (UFPI) analisam a noção de historicidade no âmbito da fenomenologia, para tratar de como nos processos de escrita da historicização na história e na comunicação a noção de contexto está sendo trabalhada. A discussão ser e tempo inaugurada pela fenomenologia de Martin Heidegger retoma como possibilidade analítica dos modos de comunicação de escravos brasileiros no século XIX.

A segunda parte do dossiê conta com artigos que, a partir de análises específicas, problematizam as relações entre contextos, produtos e processos comunicacionais. Nuno Manna (UFBA), Phellipy Jácome (UFMG) e Thiago Ferreira (UFBA), em "Recontextualizações do -ismo: disputas em torno do jornalismo 'em crise", fazem um exercício de historicização da ideia de crise do jornalismo por diversos autores e agentes midiáticos contemporâneos. Os autores buscam demonstrar, ainda, como que, ao mesmo tempo em que se consolidam discursos sobre a crise, se levantam novos grupos e coletivos como Mídia Ninja e Jornalistas Livres, que buscam redefinir o jornalismo na medida em que o reinvindicam como definição e identidade do/no seu próprio fazer.

Itala Maduell (PUC-Rio), Fernanda Lima Lopes (UFRJ) e Mauricio Duarte (UFRJ), em "Representações cinematográficas do jornalismo investigativo em Todos os homens do presidente (1976) e Spotlight (2015)", abordam por meio da representação de dois filmes do jornalismo investigativo a mobilização de estereótipos duradouros (credibilidade, neutralidade, heroísmo). Já Jussara Maia (UFRB), Igor Sacramento (Fiocruz/UFRJ) e Valéria Vilas Bôas (UFBA), em "O controle do corpo feminino no programa Encontro Fátima Bernardes: subjetividade, texto e contexto", operam a contextualização dos processos comunicacionais por meio dos discursos sobre a mulher no programa apresentado por Fátima Bernardes na TV Globo e nos comentários deixados por telespectadoras no perfil oficial do programa no Twitter. Dessa forma, a contextualização assume uma função dupla no artigo: demonstra as formas de posicionamento do sujeito mulher por meio dos discursos do programa e dos comentários em relação a formação discursiva patriarcal brasileira, mas também 
exploram a comunicação como um processo que envolve produção, circulação e apropriação de sentidos sociais.

Por fim, também tendo a televisão como objeto de análise, em "Performances e memória em expressões televisivas", Jorge Cardoso (UFRB/ UFBA), Juliana Gutmann (UFBA) e Rafael José Azevedo (UFMG) analisam dois programas, Ensaio (TV Cultura) e Jornal da MTV, a partir da perspectiva dos estudos da performance. Os autores discutem como a força performativa das imagens permitem novas formas de análise das relações entre televisão e música na cultura contemporânea.

Em seu conjunto, todos os artigos indicam como contextualizar se apresenta menos como a recuperação de uma moldura ou pano-de-fundo histórico e mais como um delicado, complexo e desafiador caminho incerto para informar-nos sobre diferentes fenômenos, processos e produtos. Esperamos que todos os leitores e todas as leitoras tenham ótimas experiências com esses artigos e que eles estimulem não apenas um outro olhar sobre contexto e contextualização como também outras pesquisas e trabalhos sobre as historicidades dos processos comunicacionais.

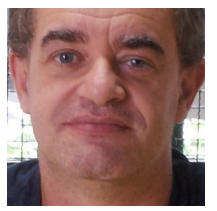

Bruno Souza Leal < brunosleal@gmail.com>

Universidade Federal de Minas Gerais

Avenida Presidente Antônio Carlos, 6627 - Pampulha

31270-901 - Belo Horizonte (MG) - Brasil

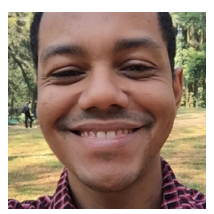

Igor Sacramento <igorsacramento@gmail.com>

Universidade Federal do Rio de Janeiro (UFRJ)

Avenida Pasteur, 250 - Praia Vermelha

22290-240 - Rio de Janeiro (RJ) - Brasil

Itania Gomes <itania@ufba.br>

Universidade Federal da Bahia (UFBA)

Av. Barão de Geremoabo, $s / n^{\circ}-$ Campus de Ondina

40170-115 - Salvador (BA) - Brasil 